\title{
Multi-item EOQ model with demand dependent on unit price
}

\author{
R. Kasthuri ${ }^{1}$, C. V. Seshaiah ${ }^{2}$ \\ ${ }^{1}$ Department of Mathematics, Sri Ramakrishna Engineering College, Coimbatore, TN, IN \\ ${ }^{2}$ Department of Mathematics, Sri Ramakrishna Engineering College, Coimbatore, Tamilnadu, India
}

\section{Email address:}

kasthuripremkumar@yahoo.com (R. Kasthuri)

\section{To cite this article:}

R. Kasthuri, C.V.Seshaiah. Multi-Item EOQ Model with Demand Dependent on Unit Price. Applied and Computational Mathematics. Vol. 2, No. 6, 2013, pp. 149-151. doi: 10.11648/j.acm.20130206.17

\begin{abstract}
A multi-item inventory model with demand dependent on unit cost without shortages is discussed in this paper. This paper presents a mathematical model of inventory control problem for determining the minimum total cost with limited storage space and investment. Apart from this, the warehouse space in the selling store is considered in volume. The model is solved using Kuhn-Tucker conditions method. The model is illustrated with a numerical example assuming unit price in fuzzy environment.
\end{abstract}

Keywords: Inventory, Rate Of Production, KKT Conditions, Demand Dependent On Unit Cost, Fuzzy Unit Cost, Triangular Fuzzy Number

\section{Introduction}

The constrained multi-item inventory model had been treated by many researchers. Maloney and Klein [5] discussed constrained multi-item inventory systems: an implicit approach using algorithms method. Abou-Ei-Ata and Kotb [1] developed a crisp inventory model under two restrictions. The pioneer work began by Cheng [3], who studied an EOQ model with demand dependent unit cost of single-item using geometric programming.

In any industry, the inventories are essential but they mean lockup of capital. The excess inventories are undesirable, which calls for controlling the inventories in the most profitable way. The different types of costs [ordering cost, carrying cost, etc] involved in inventory problems affect efficiency of a inventory control problem.

Silver [1985] designed the classical inventory problems by considering that the demand rate of an item is constant and deterministic and that the unit price of an item is considered to be constant and independent in nature. But in practical situation unit price and demand rate of an item may be related to each other. When the demand of an item is high, an item is produced in large numbers fixed costs of production are spread over a large number of items. Hence the unit price of an item inversely related to the demand of that item.

Zadeh [1965] first gave the concept of fuzzy set theory.
Later on, Bellman and Zadeh [1970] used the fuzzy set theory to the decision-making problem. Tanaka [1974] introduced the objectives as fuzzy goals over the $\alpha$-cut of a fuzzy constraint set and Zimmermann [1976] gave the concept to solve multi-objective linear programming problem. Park [1987] examined the EOQ formula in the fuzzy set theoretic perspective associating the fuzziness with the cost data. Hence we may impose warehouse space, cost parameters, number of orders, production cost etc, in fuzzy environment.

The Kuhn-Tucker conditions [11] are necessary conditions for identifying stationary points of a non-linear constrained problem subject to inequality constraints. The development of this method is based on the Lagrangean method. These conditions are also sufficient if the objective function and the solution space satisfy the conditions in the following table 1.1 .

\section{Table 1.1}

Sufficient conditions for Optimization:

\begin{tabular}{lll}
\hline $\begin{array}{l}\text { Sense of } \\
\text { optimization }\end{array}$ & Required conditions & \\
\hline & Objective function & Solution space \\
Maximization & Concave & Convex Set \\
Minimization & Convex & Convex Set \\
\hline
\end{tabular}

The conditions for establishing the sufficiency of the Kuhn-Tucker Conditions [4] are summarized in the 
following table 1.2

Table 1.2

Kuhn-Tucker conditions:

\begin{tabular}{ll}
\hline Problem & Kuhn-Tucker conditions \\
\hline 1.Max $\mathrm{z}=\mathrm{f}(\mathrm{X})$ & $\frac{\partial}{\partial x_{j}} f(X)-\sum_{i=1}^{m} \lambda_{i} \frac{\partial}{\partial x_{j}} h^{i}(X)=0$ \\
subject to $\mathrm{h}^{\mathrm{i}}(\mathrm{X}) \leq 0$ & $\lambda_{i} h^{i}(X)=0, h^{i}(X) \leq 0, i=1,2, \ldots . m$ \\
$\mathrm{X} \geq 0, \mathrm{i}=1,2, \ldots \ldots \mathrm{m}$ & $\lambda_{i} \geq 0, i=1,2, \ldots \ldots . m$ \\
& $\frac{\partial}{\partial x_{j}} f(X)-\sum_{i=1}^{m} \lambda_{i} \frac{\partial}{\partial x_{j}} h^{i}(X)=0$ \\
2.Min $\mathrm{z}=\mathrm{f}(\mathrm{X})$ & $\lambda_{i} h^{i}(X)=0, h^{i}(X) \geq 0, i=1,2, \ldots . m$ \\
subject to $\mathrm{h}^{\mathrm{i}}(\mathrm{X}) \geq 0$ & $\lambda_{i} \geq 0, i=1,2, \ldots \ldots . m$ \\
$\mathrm{X} \geq 0, \mathrm{i}=1,2, \ldots \ldots \mathrm{m}$ & \\
\hline
\end{tabular}

In this paper, multi-item fuzzy inventory model is considered under three constraints such as warehouse space constraint, investment amount constraint and the third one is the percentage of utilization of volume of the warehouse space. Here the volumes of the unit items are taken for calculations. The demand is dependent on unit cost and the unit cost is taken in fuzzy environment. The unit cost and lot size are decision variables. The problem is solved using Karush-Kuhn-Tucker Conditions method.

\section{2 .Assumptions and Notations}

We define the following notations in the model.

\section{Notations}

$\mathrm{n}=$ number of items

$\mathrm{B}=$ Total investment cost for replenishment

$1=$ inside length of warehouse

$\mathrm{b}=$ inside breadth of warehouse

$\mathrm{h}=$ maximum height of shelf

$\mathrm{V}=$ Volume of warehouse

$\mathrm{V}_{\mathrm{w}}=$ Percentage of utilization of volume of warehouse.

For $i^{\text {th }}$ item: $(i=1,2, \ldots$

$\mathrm{D}_{\mathrm{i}}=\mathrm{D}_{\mathrm{i}}\left(\mathrm{p}_{\mathrm{i}}\right)$ demand rate[ function of unit cost price]

$\mathrm{Q}_{\mathrm{i}}=$ lot size (decision variable)

$\mathrm{S}_{\mathrm{i}}=$ Set-up cost for the $i^{\text {th }}$ item

$\mathrm{H}_{\mathrm{i}}=$ Inventory holding cost per unit item

$\mathrm{p}_{\mathrm{i}}=$ price per unit item ( fuzzy decision variable)

$\mathrm{l}_{\mathrm{i}}=$ Length of unit item $\mathrm{i}$

$b_{i}=$ breadth of unit item $i$

$\mathrm{h}_{\mathrm{i}}=$ height of unit item $\mathrm{i}$

$\mathrm{v}_{\mathrm{i}}=$ Volume of unit item $\mathrm{i}$

$\mathrm{d}_{\mathrm{i}}=$ the annual rate of production for the $\mathrm{i}^{\text {th }}$ item

$\mathrm{TC}\left(\mathrm{p}_{\mathrm{i}}, \mathrm{Q}_{\mathrm{i}}\right)=$ expected annual total cost

\section{Assumptions}

The basic assumptions about the model are:

1. Replenishment is instantaneous.

2. No back-order is allowed.

3. Lead-time is zero.
4. demand is related to the unit price as:

$$
D_{i}=\frac{A_{i}}{p_{i}^{\beta_{i}}}=A_{i} p_{i}^{-\beta_{i}}
$$

where $\mathrm{A}_{\mathrm{i}}(>0)$ and $\beta_{\mathrm{i}}\left(0<\beta_{\mathrm{i}}<1\right)$ are constants and real numbers selected to provide the best fit of the estimated price function. $A_{i}>0$ is an obvious condition since both $D_{i}$ and $\mathrm{p}_{\mathrm{i}}$ must be non-negative.

\section{Formulation of Inventory Model}

The objective of the inventory model is to minimize the annual relevant total cost (i.e the sum of production, setup and inventory carrying costs) which according to the basic assumptions of the EOQ model is,

Total cost $=$ Production cost + Set up cost + Holding cost Total average cost of the ith item is

$$
\begin{gathered}
\operatorname{MinTC}\left(p_{i}, Q_{i}\right) ₹ p_{i} D_{i}+\frac{S_{i} D_{i}}{Q_{i}}+\frac{1}{2}\left[-\frac{D_{i}}{d_{i}}\right] Q_{i} H_{i} \\
=A_{i} p_{i}^{1-\beta_{i}}+\frac{A_{i} S_{i}}{Q_{i}} p_{i}^{-\beta_{i}}+\frac{1}{2}\left[1-\frac{A_{i} p_{i}^{-\beta_{i}}}{d_{i}}\right] Q_{i} H_{i}
\end{gathered}
$$

for $i=1,2,3, \ldots \ldots \ldots n$

$\operatorname{Min} T C\left(p_{i}, Q_{i}\right)=$

$\sum_{i=1}^{n}\left[A_{i} p_{i}^{1-\beta_{i}}+\frac{A_{i} S_{i}}{Q_{i}} p_{i}^{-\beta_{i}}+\frac{1}{2}\left[1-\frac{A_{i} p_{i}^{-\beta_{i}}}{d_{i}}\right] Q_{i} H_{i}\right]$

There are some restrictions on available resources in inventory problems that cannot be ignored to derive the optimal total cost.

(i) The limitation on the available warehouse space in the store

$$
\sum_{i=1}^{n} v_{i} Q_{i} \leq V
$$

(ii) The upper limit of the total amount investment $\sum_{i=1}^{n} p_{i} Q_{i} \leq B$

where $p_{i}, Q_{i}>0 \quad(i=1,2 \ldots . n)$

(iii) Percentage of utilization of volume of the warehouse

$$
\frac{V X V_{W}}{\left(\sum_{i=1}^{n} v_{i} Q_{i}\right) 100}=1,0 \leq V_{W} \leq 100
$$

\section{Membership Function}

The membership function for the triangular fuzzy variable $p_{i}$ is defined as follows 


$$
\mu_{p_{i}}(X)=\left\{\begin{array}{l}
\frac{x-a_{1}}{a_{2}-a_{1}}, a_{1} \leq x \leq a_{2} \\
\frac{x-a_{3}}{a_{2}-a_{3}}, a_{2} \leq x \leq a_{3} \\
0, \text { otherwise }
\end{array}\right\}
$$

\section{Numerical Example}

The model is illustrated for one item ( $\mathrm{i}=1)$ and also the common parametric values assumed for the given model are

$$
\text { For } \mathrm{i}=1 \text {, }
$$

$\mathrm{i}=1, \mathrm{~A}_{1}=113, \mathrm{~S}_{1}=\$ 100, \mathrm{H}_{1}=\$ 1, \mathrm{~B}=\$ 1400, \mathrm{l}_{1}=2 \mathrm{~m}$, $\mathrm{b}_{1}=3 \mathrm{~m}, \mathrm{~h}_{1}=4 \mathrm{~m}$,

$\mathrm{l}=10 \mathrm{~m}, \mathrm{~b}=12 \mathrm{~m}, \mathrm{~h}=30 \mathrm{~m} \quad \mathrm{~d}_{1}=300$ units and $\mathrm{p}=$ $(3,15,27)$

From the given values $\mathrm{v}_{1}=24$ cubic $\mathrm{m}$ and $\mathrm{V}=3600$ cubic $\mathrm{m}$.

The proposed model is solved by Karush-Kuhn-Tucker conditions and the optimal results are presented in the table 5.1

Table 5.1

Optimal solution table:

\begin{tabular}{lllllll}
\hline$\beta_{\mathbf{1}}$ & $\mathbf{p}_{\mathbf{1}}$ & $\mathbf{Q}_{\mathbf{1}}$ & $\mathbf{D}_{\mathbf{1}}$ & $\begin{array}{l}\boldsymbol{\mu}_{\mathbf{P} 1} \\
\text { value }\end{array}$ & $\mathbf{V}_{\mathbf{W}}$ & $\begin{array}{l}\text { Expect } \\
\text { ed } \\
\text { Total } \\
\text { cost }\end{array}$ \\
\hline 0.82 & 4.47 & 83.34 & 33.10 & 0.12 & 55.56 & 224.75 \\
0.85 & 8.63 & 62.66 & 18.10 & 0.47 & 41.8 & 214.44 \\
0.88 & 16 & 46.004 & 9.85 & 0.92 & 30.67 & 201.26 \\
0.92 & 42.46 & 27.18 & 3.59 & 0 & 18 & 179.16 \\
\hline
\end{tabular}

From the above table it follows that 16 has the maximum membership value 0.92 .

Hence the required optimum solution is $p_{1}=16, Q 1=46$

Minimum expected Total cost $=\$ 201.26$

\section{Conclusion}

This paper is dedicated to solve a multi-item inventory problem for determining the total annual cost using KarushKuhn-Tucker conditions method. The decision variables namely the unit price and demand are calculated by varying the values of the parameter $\beta$. The solution table shows that as the parametric value $\beta$ increases, the unit price also increases whereas the demand, lot size and the percentage of utilization of volume decreases. This work can be extended by varying the constraints like limited budgetary, setup cost etc.

\section{References}

[1] M.O.Abou-EL-Ata and K.A.M.Kotb , Multi-Item EOQ Inventory model with varying Holding cost under two restrictions: A Geometric programming Approach,Production Planning \& Control, 6(1997),608-611.

[2] R.E.Bellman,L.A.Zadeh,Decision -making in a fuzzy environment Management Science 17(4)(1970) B141-B164

[3] T.C.E.Cheng, An Economic Order Quantity Model with Demand-Dependent unit cost, European Journal of Operational Research, 40(1989),252-256.

[4] P.K.Gupta, Man Mohan, Problems in operations Research (Methods \& Solutions), S.Chand Co., (2003)609-610.

[5] B.M.Maloney and C.M. Klein, Constrained Multi-Item Inventory systems: An Implicit Approach, Computers Ops. Res. 6(1993),639-649.

[6] Nirmal Kumar Mandal, Et. al., "Multi-objective fuzzy inventory model with three constraints: a geometric programming approach", Fuzzy sets and systems, (150), 87106,2005

[7] K.S.Park,Fuzzy set theoretic interpretation of economic order quantity, IEEE Trans. Systems Man Cybernet. 17 (6) (1987) 1082-1084.

[8] G.Sommer,Fuzzy inventory scheduling ,in:G.Lasker(Ed.),Applied Systems and Cybernetics, Vol.VI, Academic Press.New York,1981.

[9] E. A. Silver and R. Peterson, "Decision Systems for Inventory Management and Production Planning," John Wiley, New York, 1985.

[10] H. Tanaka, T. Okuda and K. Asai, "On Fuzzy Mathematical Programming," Journal of Cybernetics, Vol. 3, No. 4, 1974, pp. 37-46. doi:10.1080/01969727308545912

[11] H.A.Taha, Operations Research an introduction , PrenticeHall of India(2005)725-728.

[12] L.A.Zadeh "Fuzzy sets ,Inform.and Control (1965) 338-353.

[13] H.J.Zimmermann , "Discription and optimization of fuzzy systems”, Internat .J. General Systems 2(4) (1976) 209-215. 